\title{
BIOgeografias na Fronteira Sul (Brasil/Paraguai/Bolívia) ${ }^{1}$
}

\author{
BIOgeografías en la Frontera Sur (Brasil/Paraguay/Bolivia) \\ BIOgeographies in the South Frontier (Brazil/Paraguay/Bolivia)
}

\author{
Marcos Antônio Bessa-Oliveira²
}

\begin{abstract}
Resumo
A produção artística de Mato Grosso do Sul esteve nos últimos anos vinculada a duas noções de arte e cultura bovinas: uma, a bovinocultura como repertório cultural das produções artísticas; outra, o bovinoculturismo como modelo para as produções artísticas. Ambas "culturas bovinas" - bovinocultura e bovinoculturismo - esboçam opções de discussões acerca das questões às quais estão envoltas. Uma delas, à bovinocultura, é que esta noção está relacionada com trabalhos artísticos que se valem do boi como característica cultural intrínseca às biogeografias fronteiriças dos sul-mato-grossenses. Já o bovinoculturismo, podemos dizer que uma de suas noções na cultura está posta por uma sistematização de controle dos sujeitos dessas biogeografias das produções artísticas locais nessa mesma fronteira sul. A primeira toma da "imagem" do boi como paisagem biográfica constituinte da cultura local, enquanto a segunda se vale do boi real a partir das relações mercadológicas instauradas pelo/do agronegócio em que o boi vale mais que uma vida (in)(h)umana. Portanto, tomando dessas primeiras ideias, este trabalho quer discutir acerca da "cultura do boi" como repositório cultural e como controle da cultura local sul-mato-grossense nessa tríplice fronteira (Brasil/Paraguai/Bolívia) a partir das noções de biogeografia e paisagens biográficas como epistemes para uma arte descolonial. Nesse sentido, a ideia é discutir trabalhos artísticos e as biogeografias dessa fronteira sul, nas diferentes linguagens com suas identidades, que estão produzindo arte e conhecimento e circulando entre os espaços, tomando como ilustração a "imagem" simbólica ou real - do boi, para produção ou inscrição.
\end{abstract}

Palavras-Chave: BIOgeografias; Bovinocultura; Bovinoculturismo; Mato Grosso do Sul; Pós-colonialidade.

\section{Resumen}

La producción artística de Mato Grosso do Sul estuvo en los últimos años vinculada a dos nociones de arte y cultura bovinas: una, la bovinocultura como repertorio cultural de las producciones artísticas; otra, el bovinoculturismo como modelo para las producciones artísticas. Ambas "culturas bovinas" - bovinocultura y bovinoculturismo - esbozan opciones de discusiones sobre las cuestiones a las que están envueltas. Una de ellas, a la bovinocultura, es que esta noción está relacionada con trabajos artísticos que se valen del buey como característica cultural intrínseca a las biogeografías fronterizas de los sul-mato-grossenses. El bovinoculturismo, podemos decir que una de sus nociones en la cultura está puesta por una sistematización de control de los sujetos de esas biogeografías de las producciones artísticas locales en esa misma frontera sur. La primera toma de la "imagen" del buey como paisaje biográfico constituyente de la cultura local, mientras que la segunda se vale del buey real a partir de las relaciones mercadológicas instauradas por el/del agronegocio en que el buey vale más que una vida (in)(h)umana. Por lo tanto, teniendo estas ideas tempranas, este documento quiere hablar sobre "la cultura de ganado" como un repositorio cultural y cómo el control del Surmato-grossense local en esta triple frontera (Brasil/Paraguay/Bolivia) a partir de las nociones de biogeografía y paisajes biográficos como epistemes de un arte decolonial. En este sentido, la idea es discutir obra y biogeografias del esta frontera sur, en diferentes lenguajes con sus identidades, que están produciendo arte y

\footnotetext{
${ }^{1}$ Este texto está vinculada a uma pesquisa maior cujo título e dados são (Retirados para não haver identificação)

${ }^{2}$ Doutor em Artes Visuais; Professor do curso de Artes Cênicas e do Mestrado Profissional em Educação PROFEDUC - UEMS/UUCG; NAV(r)E - Núcleo de Artes Visuais em (re)Verificações Epistemológicas; Campo Grande, Mato Grosso do Sul, Brasil; marcosbessa2001@uol.com.br. Trabalho apresentado no I Seminário Latino-Americano de Estudos em Cultura - SEMLACult, Foz do Iguaçu/PR, Brasil, 2017.
} 
conocimiento y que circulan entre los espacios, utilizando como ejemplo la "imagen” - simbólicos o reales del buey, para la producción o el registro.

Palabras claves: BIOgeografías; Bovinocultura; Bovinoculturismo; Mato Grosso do Sul; Post-colonialidad.

\begin{abstract}
The artistic production of Mato Grosso do Sul has in recent years been almost always linked to two notions of bovine art and culture: one, bovine culture as a cultural repertoire of artistic productions; Another, bovinebuilding as a model for artistic productions. Both "bovine cultures" - bovine culture and bovinebuilding - outline options for discussions about the issues to which they are involved. One of them, to bovinoocultura, is that this notion is related to artistic works that use the ox as a cultural characteristic intrinsic to the border biogeographies of the south-mato-grossenses. Bovine bodybuilding, we can say that one of its notions in the culture is put by a systematization of control of the subjects of these biogeographies of the local artistic productions in this same southern border. The first take of the "image" of the ox as a biographical landscape constituent of local culture, while the second uses the real ox from the market relations established by the agribusiness in which the ox is worth more than a no(nh)uman life. Therefore, taking these first ideas, this work wants to discuss the "ox culture" as a cultural repository and as a control of the local culture of South-Mato Grosso on this tri-border frontier (Brazil/Paraguay/Bolivia) from the notions of biogeography and landscapes Biographical as epistemes for a decolonial art. In this sense, the idea is to discuss artistic works and the biogeographies of this southern border, in the different languages with their identities, that are producing art and knowledge and circulating between spaces, taking as illustration the "image" - symbolic or real - of the ox, for production or inscription.
\end{abstract}

Keywords: BIOgeographs; Bovinocultura; Bovinoculturismo; Mato Grosso do Sul; Postcoloniality.

\title{
1. Introdução
}

A produção artística de Mato Grosso do Sul - desde a sua constituição como estado da Federação Brasileira, após a divisão do estado de Mato Grosso em 1977 - tenta estabelecer-se a partir de características que ressaltem sua "individualidade" local em um cenário nacional cultural brasileiro marcado por diferentes características que sustentam as supostas “individualidades” dos outros Estados. Desde essa divisão política, econômica e cultural da parte sul do estado de Mato Grosso, MS vem si constituindo como um rincão cultural, político e econômico da "cultura do boi". Político e economicamente constituiu-se através das fazendas que fazem da e sustetam uma das maiores criações de gado leiteiro e de corte do país, bem como exaltam a fama de um dos maiores plantadores de soja, milho, trigo, entre outras especiarias do grão, ambos com fins para exportação para o mundo Ocidental e Oriental - na mídia diária vemos os vivas ao Agronegócio: ( $O$ Agro é Pop) vai das empresas automobilísticas aos objetos e lugares nunca antes pensados como prováveis frutos da "indústria" agronômica. Já em relação à questão cultural, Mato Grosso do Sul tem se apegado muito intimamente aos rincões político e econômico para suscitação dessa noção de "cultura do boi". Nesse sentido, cabe dizer que a noção de "cultura do boi" ou "cultura bovina", aqui em nossa questão a ser tratada, está atravessada também, no caso dessa produção artística da tríplice fronteira Brasil/Paraguai/Bolívia, não exclusivamente pela imagem do boi como 
animal presente nos corpos, telas, esculturas, vídeos etc. Mas corrobora também essa constante "do boi" na produção artística local as paisagens, as iconografias indígenas e de matrizes africanas, as evidências, umas ora mais, muitas outras ora menos, de culturas nacionais que circundam os limites de Mato Grosso do Sul e de culturas internacionais que hoje compõem a situação social, cultural, econômica e política do Estado. Portanto, ao tratar de "cultura bovina" ou da "cultura do boi" em Mato Grosso do Sul estaremos sempre tendo em mente também as características locais do lugar enquanto região geográfica, mas ao mesmo tempo as "marcas" culturais e/ou políticas que constituem essas produções artísticas e sujeitos locais.

Para tratar das questões aqui $e x$-postas (inclusive as que estão por vir), tendo em vista tratar de BIOgeografias, situo melhor o lócus enunciativo das minhas argumentações. Cabe salientar que priorizo uma episteme outra, e com isso torna-se condição para compreensão dessas alegações postas levarem em consideração este fato para compreendê-las. Assim, tomo de Mato Grosso do Sul que é o lócus enunciativo de onde penso, produzo e pesquiso que faz fronteira com o Paraguai e a Bolívia. Lugar de trânsito (tráfico) de toda a natureza propriamente dita: drogas, influências, culturas, contrabandos, produções culturais e de sujeitos de línguas, hábitos e modos diferentes. Ainda, Mato Grosso do Sul faz limite com cinco Estados Brasileiros: Minas Gerais, São Paulo, Goiás, Paraná e Mato Grosso, este último de quem fora divido geográfico, politicamente (e culturalmente) em 1977. As relações entre os Estados se estabelecem de todas as formas, mas, culturalmente falando, há uma melancolia ao que se referem a MT em relação aos sul-mato-grossenses. ${ }^{3}$ Mato Grosso do Sul, na arte, de modo geral, ainda tem sua promoção sustentada (precariamente) no Poder Público: Municipais e Estadual, normalmente, mas em alguns raros casos alguns artistas conseguem apoio do Governo Federal via parcos editais que ainda contemplam produções artísticas fora dos eixos Rio-São Paulo. Este ponto é fator importante para situar as práticas artísticas locais no que tange às representações e visualidades que essas produções exprimem do e para o lugar. Sabe-se desde muito tempo (do clássico ao moderno) que obras artísticas avalizadas por poderes instituídos sempre privilegiam imagens institucionais. E neste caso, artistas locais Contemporâneos ou Artífices atuais — tomam nas suas produções de um discurso identitário que circunscreve obras/sujeitos nas mesmas ideias de identidades do passado: estável e de representação de muitos por um.

\footnotetext{
${ }^{3}$ Sobre isso, vale ver outro artigo nosso já publicado. (AUTOR; NOLASCO, 2010).
} 
Neste sentido, cabe uma pergunta: qual é o tempo tratado nas produções artísticas atuais? Seja na produção artística rotulada de Arte Contemporânea, seja em produções da/na atualidade, qual é o tempo narrativo que esses artistas têm abordado em suas obras plásticas? Portanto, cabe também no âmbito deste artigo, pensarmos nisso tendo em vistas os possíveis agoras (se eles existem) na produção artística de artistas do século XXI que estão dizendo tratar do nosso tempo em questão, mas também em vista da ideia de que alguns artistas, através de suas obras, apenas agouram o passado áureo das artes plásticas (clássicas e modernas) e que outros tratam suas obras como objetos em ágoras clássicas visando simplesmente à situação de evidência e popularidade na atualidade. Mas para isso, duas questões são necessárias serem esclarecidas antes de dar início à discussão propriamente dita a qual se pretende neste artigo: o tema posto pelos termos "produção artística contemporânea" e o "lócus geoistórico enunciativo" nos quais circunscrevem a discussão: Mato Grosso do Sul! A primeira refere-se ao recorte artístico do qual tratarei: a produção artístico-plástica e artistas inscritos sob o rótulo de arte contemporânea e da produção também plástica e de artistas que estão trabalhando neste momento presente. Ora mais, ora menos, serão privilegiadas características de uma arte contemporânea ou de uma produção desenvolvida na contemporaneidade, bem como de seus artistas, para ilustração das discussões que serão aqui expostas. Pois, a ótica de (tempo) contemporâneo aqui é concordante com Katia Canton ao afirmar que:

O tempo contemporâneo surge como um elemento que perfura o espaço, substituindo a sensação de objetivação cronológica por uma circularidade plena de instabilidade. Turbulento, esse tempo parece fugaz e raso. Retira as espessuras das experiências que vivemos no mundo, afetando inexoravelmente nossas noções de história, de memória, de pertencimento. O grande perigo desse tempo raso é justamente a falta de espessura, a sensação de atemporalidade e de que, no lugar de processo de deslocamento, existe apenas o agora. (CANTON, 2009, p. 20)

O outro ponto de articulação das discussões toma o estado de Mato Grosso do Sul como cenário por entender a demanda necessária de se pensar sobre e a partir dessas produções e artistas que estão emergindo no local cultural e geoistórico situado à margem da fronteira entre Brasil-Paraguai-Bolívia como dito. Mas, a priori, se de algum modo a questão parecerá centrada em um lócus enunciativo simplesmente por predileção geográfica, cabe dizer que a demanda para pensar sobre e a partir de tais situações (históricas e/ou geográficas) que serão expostas é ainda emergente nesse lócus. Antes, porque venho acompanhando o desenvolvimento da produção artística local sul-mato-grossense bem de perto a mais de 10 anos. (AUTOR, 2012) Em segundo lugar porque, se de algum modo, algumas produções e artistas estão acompanhando as mudanças dos tempos, outros parecem apenas continuar 
resgatando memórias e histórias sem proposição de nenhuma (re)inventação ao/no presente artístico local que, igualmente corroborado por Canton, as memórias biográficas são as que mantêm em suspensão e prolongamento as obras "na" contemporaneidade:

Nas artes, a evocação das memórias pessoais implica a construção de um lugar de resiliência, de demarcações de individualidade e impressões que se contrapõem a um panorama de comunicação à distância e de tecnologia virtual que tendem gradualmente a anular as noções de privacidade, ao mesmo tempo que dificultam trocas reais. É também o território de recriação e de reordenamento da existência um testemunho de riquezas afetivas que o artista ofereceu ou insinua ao espectador, com a cumplicidade e a intimidade de quem abre um diário. (CANTON, 2009, p. 21-22)

Nesse sentido, como exposto aqui, o que se entende por contemporâneo e por memória, história, lugar não estão circunscritos em reproduções de histórias, memórias, paisagens e arquivos do passado sem o fim de resignificações desses no presente - tanto em relação à arte, aos artistas e mais ainda em relação aos sujeitos e suas identidades multíplices - seja visando manutenção de discursos, seja com ideias de inscrição das produções locais em "lugares" (tempos e memórias) não posicionados nos seus muitos presentes.

Certamente, cabe dizer ainda que essas questões mostradas far-se-ão emergir outras tantas tão importantes quanto. Ou seja: sobre as políticas públicas das artes no Estado; sobre os espaços expositivos do Estado; a situação do mercado artístico do Estado; a formação e o ensino das artes locais; além de teorias emergentes sobre as produções artísticas desenvolvidas no estado de Mato Grosso do Sul. Mas, a princípio, tomando como ponto fundamental, parto da ideia de discutir a inscrição desse lugar enunciativo como produtor de arte - contemporânea e na contemporaneidade - o que, de maneira direta, acaba por tomar o discurso da e a crítica de arte locais sobre essas produções, artistas e sujeitos das artes sulmato-grossenses. Por conseguinte, acaba por esbarrar em questões estruturadas em discursos metodológicos e epistêmicos das pesquisas e discussões da crítica de arte local: se contemporânea ou apenas críticos/históricos - como argumentou Jacques Derrida em relação às análises puramente estruturalistas - que reproduzem discursos críticos históricos na contemporaneidade.

A atitude estruturalista e a nossa postura hoje perante a linguagem ou na linguagem não são unicamente momentos da história. Antes espanto pela linguagem como origem da história. Pela própria historicidade. É também, perante a possibilidade da palavra, e sempre já dentro dela, a repetição finalmente confessada, finalmente alargada às dimensões da cultura mundial, de uma surpresa sem medida comum com qualquer outra e com a qual se agitou aquilo que se costuma denominar pensamento ocidental, esse pensamento cujo destino consiste muito simplesmente em aumentar o seu domínio à medida que o Ocidente diminui o seu. (DERRIDA, 2009, p. 2-3) 
Vários artistas em Mato Grosso do Sul produzem argumentados em estruturas de memórias e histórias artísticas Ocidentais - clássicas e modernas - trazendo à tona um fazer artístico que se limita em (re)produzir o passado no presente. Já outros artistas locais produzem tomando da memória biográfica de cada um para ressaltar características do espaço geográfico sulmato-grossense, sem priorizar memórias e histórias antigas. Sem fazer nenhum juízo de puro valor, ainda que por ora, mesmo porque os conceitos de memória e até o de arquivo, segundo Jacques Derrida, não estão ligados exclusivamente ao passado, buscarei tratar de alguns desses artistas que lançam mão de memórias (próprias e alheias) para construções artísticas do(s) no(s) presente(s) (CANTON, 2009): "agoras" da/na contemporaneidade. A ideia, a princípio, é tratar de produções e artistas que estão produzindo memórias e histórias ou apenas reproduzindo-as no presente.

O boi, portanto, como personagem real dessa produção incultural personifica o que não tem personalidade, aquele que não tem vida própria. Ou seja, a realidade do boi intrínseca à produção artística de Mato Grosso do Sul entendida como cultural dá vida comercial e mercantil ao índio, ao sujeito distinto dos gêneros homem/mulher, ao negro, ao pobre, ao suburbano e ao artista que não tem "reconhecimento" estatal. Portanto, o Agronegócio do boi acaba por tratar esses sujeitos inumanos - como se esses fossem humanos e participassem da divisão da carne assim como das terras no Estado - quando na verdade as obras tratam apenas de interesses dos discursos dos poderes. Por conseguinte, a vida daquele animal acaba por valer muito mais do que as vidas desses sujeitos humanos que na verdade são inumanos em relação ao boi; por isso esses sujeitos são vistos pelos poderes políticos, econômicos e também os culturais como (in)(h)umano. Portanto, o boi aqui toma a cena — "Agouro, Ágora, Agora" - por dois vieses bem distintos: o boi como imagem e metáfora da cultura bovina; o boi como animal real que literalmente sustenta uma noção equivocada de cultura do boi. Ainda, três pontos, antes mesmo de situar a questão da Arte bovina em si (seja Contemporânea seja uma arte da Atualidade), ilustram: $1^{\circ}$ ) sobre o "Agouro: "Presságio, ação de prever o que acontecerá no futuro"', tomar-se-á neste trabalho da ideia de artistas que visam à inscrição de suas obras pura e exclusivamente em lugares dos discursos que as sustentam em algum lugar da arte (Contemporânea e/ou da Atualidade), por isso, serão tratados artistas que agouram para si lugares de outrem (clássico ou moderno); $2^{\circ}$ ) já a "Ágora: "Lugar de reunião, de diálogo"”" tem da ilustração de lugares que artistas visam com suas obras: galerias, museus, espaços institucionais expositivos promotores de artistas e obras 
em nossa época sem, prioritariamente, tomar como ponto de partida a relação dessas obras e artistas com o nosso tempo: o tempo dos agoras.

\begin{abstract}
As guerras e as necessidades políticas e econômicas provocam um fluxo geográfico internacional e, como consequência, os deslocamentos humanos instauram uma nova noção de identidade e de nacionalidade. O espaço flexível e instável, emblemático da era global, expande-se num tempo também marcado por instabilidade e fragmentação de informações e por excesso de imagens e estímulos de múltiplas naturezas. Tempo e espaço se redefinem na linguagem [...] [artística]. (CANTON, 2009, 31-32)
\end{abstract}

E, por fim, neste princípio em que se situa os argumentos deste trabalho, nosso último ponto, $3^{\circ}$ ) o "Agora: "Momento presente, época em que nos encontramos"” será tratado aqui exatamente como tal. Mas como agoras - vários tempos, memórias, histórias, por conseguinte sujeitos, espaços e narrativas - que corroboram as perguntas: Em tempos de vários agoras (Agouro, Ágora, Agora), ainda vivemos no passado? Como nossa produção local está tratando das BIOgeografias na Fronteira Sul (Brasil/Paraguai/Bolívia) - como cultura do boi ou como cultura de boi? Neste tempo que não é um topos da arte dos agoras, que (de)limita todas as outras questões aqui situadas, quero discutir as questões dos sujeitos-bios -, dos espaços-geos - e das narrativas-grafias - BIOgeografias, em que estão sustentadas as produções visuais da atualidade.

\title{
2. Quatro décadas de arte em Mato Grosso do Sul: balanços e desafios
}

\author{
"Arte aqui é mato. Frase de efeito? Metáfora de espírito?" \\ (FIGUEIREDO, 1990, p. 9)
}

Faz exatos 40 anos (1977-2017) uma série de pinturas inaugurou na produção artística sul-mato-grossense a temática do bovinoculturismo como "estilo" para quase toda a produção artística local. A Série de pinturas "Divisão de Mato Grosso", com pinturas realizadas nos anos de 1978 e 1979 (aqui representadas nas figuras 1, 2 e 3), do artista plástico Humberto Espíndola $^{4}$ - composta por mais de oito telas de tamanhos variados -, retratou o momento histórico da criação de Mato Grosso do Sul depois da divisão do Mato Grosso. Tratadas como do estilo da "Bovinocultura", já que o artista havia sido reconhecido por uma outra "série" de trabalhos anteriores nominados como tal, as obras dessa série "Divisão de Mato Grosso" apresentaram à produção artística local o que veio a constituir-se como um "estilo artístico"

\footnotetext{
${ }^{4}$ Todas as imagens relacionadas às obras do artista plástico Humberto Espíndola foram retiradas do site oficial do artista e constam lá como obras do acervo Museu de Arte Contemporânea - MARCO, Campo Grande-MS. Disponível em: http://www.humbertoespindola.com.br/001-index frameset.htm - acessado em: 21 de maio de 2017.
} 
para as práticas artísticas locais em quase todas as linguagens e até para a produção crítica sobre a arte local que sempre a endossou.
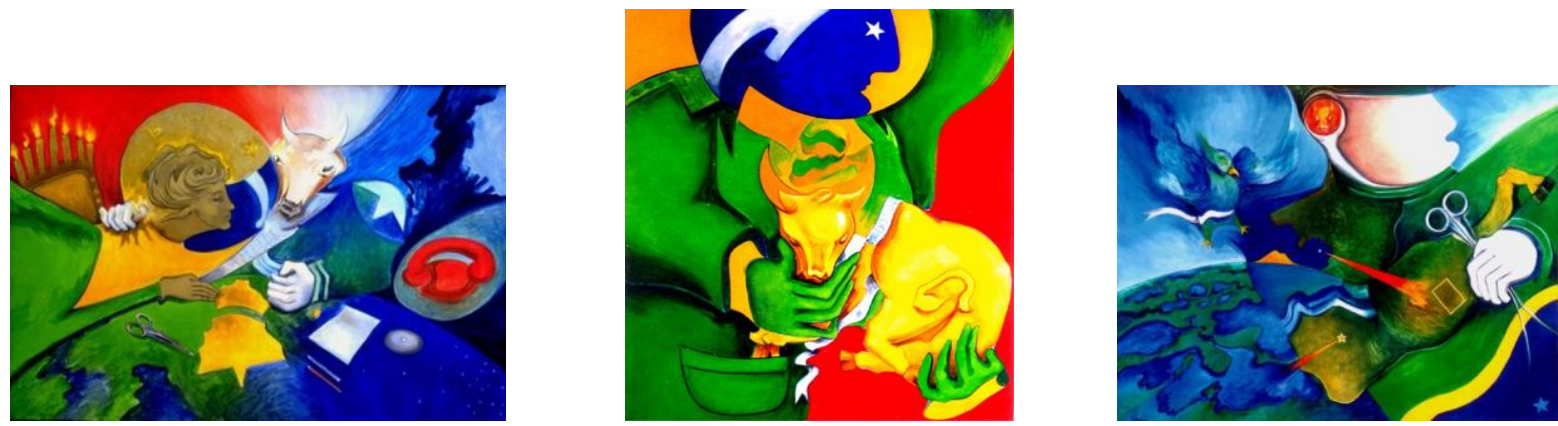

Figura 1, 2 e 3 - Pecus e Pecúnia Discutem a Divisão, 1978 - Óleo sobre tela - 130 X 170cm; O nascimento de MS, 1979 - Óleo sobre tela - 144 X 124cm e O Passeio do general, 1978 - Óleo sobre tela - 130 X $170 \mathrm{~cm}$.

Fonte: site do às obras do artista plástico Humberto Espíndola.

A produção artística local - plástica, audiovisual, cênica, musical e literária - por conseguinte esteve, nos últimos anos, vinculada a duas noções de arte e cultura bovinas que fazem ressaltar especificidades significativas no produzir arte, cultura e conhecimento, ou no reproduzir artes, culturas e (re)conhecimentos dos lugares que detém os discursos desses aqui no local também - já que os discursos do que é arte, cultura ou conhecimento imperam também em diferentes lugares: uma, a bovinocultura como mote das produções artísticas; a segunda, o bovinoculturismo como modelo para as reproduções artísticas. No primeiro caso a cultura bovina é e faz parte da constituição das práticas artísticas locais por ser compreendida a partir de um pertencimento sociocultural que está engendrado nas biogeografias locais. Já no segundo caso o bovinoculturismo visa dar continuidade e credibilidade de inscrição de algumas reproduções artísticas às ideias de arte, cultura e conhecimentos alheios migrados para o local. E neste segundo caso, há, de maneira evidente, a contribuição dos poderes políticos, econômicos e críticos para a sustentação dessa ideia de "cultura do boi" a fim de manutenção das fazendas que criam o gado e plantam os grãos.

partindo do princípio de que a imagem do boi se repete na produção artística e nas práticas culturais com tão grande intensidade por pertencer à cultura local enquanto artefato da cultura de boi do estado, supostamente em Mato Grosso do Sul o boi como representante da cultura de um lócus enunciativo onde a imagem do animal e o próprio são os mais marcados dos fragmentos da cultura do estado (econômica, política, social e cultural), deixamos de tomá-lo como marca iconográfica ou imagética estilizadas que caracterizam as práticas e produções artísticas numa dada estética homogeneizante. Quero dizer com isso que o boi passa a ser um fragmento da cultura sul-mato-grossense tão quão o são os ícones religiosos para o cristianismo, por exemplo: construções imagético-discursivas. Dessa forma, imagem do boi, ícone bovino, cultura do boi ou o próprio animal tornam-se comuns, não mais aparatos exóticos que se manifestam melhor em determinadas práticas e produções artísticas de determinados sujeitos, que caracterizam a cultura curralista desta porção sul do centro-oeste brasileiro. (AUTOR; NORONHA, 2015, p. 89) 
Todos passaram a usar a imagem do boi como iconografia estilística da produção sobre e na arte local como forma de caracterizá-la e situá-la nesse "novo" lugar político e geográfico. Acerca dessa inauguração da imagem do boi com a "Série..." na produção artística de Mato Grosso do Sul, assim como toda uma produção artística local (artes plásticas, música, audiovisual, teatro, dança, literatura, performances etc) persistente até hoje, também na crítica de arte e no ensino de arte no estado, passam obrigatoriamente pelo registro visual (imagético e real) da aura do boi nas produções artísticas: validando discursos políticos locais ou históricos hegemônicos na arte.

Ambas as "culturas bovinas" - bovinocultura e bovinoculturismo - esboçam várias opções de discussões acerca das questões as quais estão envoltas. Uma delas, em relação à bovinocultura, é que esta noção está relacionada com trabalhos artísticos que se valem do boi como característica cultural intrínseca às biogeografias fronteiriças dos sul-mato-grossenses, por isso produzem arte, cultura e conhecimento. Outra, é que a bovinocultura se inscreveria como uma "marca" (DERRIDA, 2001) que está "cerzida" a ferro quente nas identidades dos sujeitos sul-mato-grossenses: sejam eles nascidos e criados no local, sejam os que por aqui aportam e passam a viver e sobreviver dessa cultura. Já em relação ao bovinoculturismo, podemos dizer que uma de suas noções na cultura está posta por uma sistematização de controle dos sujeitos dessas biogeografias das produções artísticas locais nessa mesma fronteira sul. Quero dizer com isso que há um aparato político e econômico que insiste em fazer a manutenção do bovinoculturismo para insistência e inscrição de uma suposta característica local (na arte, na cultura e no conhecimento) em um repertório de arte, cultura e conhecimento externos trazidos e não traduzidos no local. Portanto, esses sujeitos reproduzem artes, culturas e conhecimentos que não são do local, mas estão sendo implantados como "do" local. Ora avalizados pelo poder público local - mais comumente via as Secretarias e Fundações de Culturas (Estadual e Municipal) -, ora pelos discursos críticos que endossam a presença do boi como estilo artístico, não como repertório cultural de um arquivo e uma memória locais assentados em questões e fatos sociais, políticos, culturais e mesmo econômicos (este último, caso do agronegócio), o bovinoculturismo é cultuado como estilo das artes locais. Em quase todas as linguagens da arte local é possível perceber uma “imagem" do boi como ícone que ronda a cultural local sul-mato-grossense; como se essa arte, no todo, estivesse totalmente assentada nessa imagem como única forma de construção de narrativas artísticas na atualidade. As produções artísticas então, partindo do princípio de produzir arte local, inscrevem as produções artísticas em estilos e movimentos artísticos 
construídos pela História da Arte europeia como única forma de (re)produzirem “inventAÇÕES” artísticas na atualidade.

Esta última questão faz ressaltar, por exemplo, que há alguns artistas e supostos críticos locais que são mantidos para promoverem um discurso artístico que esteja ancorando à ideia da arte, da cultura e do conhecimento que têm que obrigatoriamente passar pela imagem do boi. Como também é possível dizer que há nessa relação o continuísmo dos mesmos sistemas políticos e econômicos que, a fim de continuar a promoção dos mesmos artistas e críticos, sustentam a ex-posição desses artistas e críticos da/na situação. Ou seja, forma-se um círculo vicioso em volta da produção artística local que mantêm o boi, a paisagem e outras iconografias extra-vagantes como genuinamente regionais nas reproduções locais. O que, de certa forma, já nos leva a questionar: é possível individualizar algo para torná-lo local como assim o quer o sistema (político e econômico)? Ou, como devemos tratar as particularidades, ou as "rasuras", como também definiu Derrida, que alteram e fazem alterações em quem habita e transita nos diferentes lados das fronteiras que distanciam, separam, mas também aproximam e amalgamam (HISSA, 2002) as biogeografias? Essas são questões, entre muitas outras que surgem, das quais temos que tratar de maneira íntima para discorrer sobre as práticas artísticas locais produzirem ou reproduzirem arte, cultura e conhecimento no local dessa tríplice fronteira (Brasil/Paraguai/Bolívia). Daí contata-se também a concordância de que "a fronteira geográfica é lugar de separação, mas o é também local de aproximação das diferenças e semelhanças entre os lugares, sujeitos e suas práticas artístico-culturais." Pois, estas, situam-se em lugar do "vazio", como trata também Cássio Hissa sobre a significação da fronteira quando é vista como lugar ingovernável, mas que preferimos tomar como lugar de enunciação e que faz emergir arte, cultura e conhecimento que, aí sim, não são dominados pelos governos que instauram as fronteiras. Tomando disso, a noção de fronteira deste trabalho é de ordem epistêmica, conceitual e cultural, mas o é também real tendo em vista que as práticas e sujeitos transitam esses dois espaços, ora sob o aval do Estado-nação, ora invisíveis aos olhos dos poderes que estabelecem lados binários nos espaços das fronteiras. Do mesmo jeito, essas biogeografias artísticas e identitárias tornam-se e tomam de um aparato cultural que não se inscreve na ordem do discurso do bovinoculturismo artístico, mas que pode tomar da bovinocultura como artefato da arte, da cultura e do conhecimento; que fazem emergir desses muitos lugares que habi(li)tam as fronteiras e que, por conseguinte, demandam pensá-las a partir da noção de fronteira enquanto lugar epistêmico. 
Por que precisamos de pensar a partir da fronteira? Onde isso vai levar? Estabelecimento do descolonial como fatura da epistemologia do ponto zero. $\mathrm{O}$ pensamento de fronteira prevê, em princípio, tipos diferentes de atores teóricos e princípios do conhecimento que deslocam a modernidade europeia (que articulou o conceito da teoria das ciências sociais e humanas) e capacita aqueles que foram epistemologicamente enfraquecido pela teo[logia-política] e ego-política do conhecimento. (MIGNOLO, 2009, p. 3) (Tradução livre minha)

Por tudo isso colocado fica evidente a necessidade de pensar as fronteiras para além das ideias de limites demarcatórios estabelecidos por discursos hegemônicos políticos e econômicos, que engessam e aprisionam os discursos da arte, da cultura ou do conhecimento. E, igualmente emergente, faz-se necessário evidenciar características que estão implícitas nessas práticas, sujeitos e lugares que os discursos dominantes sequer almejaram um dia pensar. Seja pela ótica de quem dá valor aos discursos artísticos (a crítica de arte e/ou as teorias sobre as artes dos locais), ou ainda seja pela ótica de quem deveria viabilizar as produções de arte, cultura e conhecimentos dos lugares fora dos eixos que nem ao menos pagam as contas com essa parcela da população. E, do mesmo jeito, seja também pelos próprios artistas que devem sim unir-se, mas nunca em prol de si próprios a fim de se alto nominarem locais reproduzindo arte extra-local, mas à favor de produzir arte, cultura e conhecimento a partir do local. Eis ai a grande dificuldade de uma arte, uma cultura e um conhecimento que são pensados única e exclusivamente a partir de imagens e paisagens do boi como animal-vivo.

Essas questões fazem esboçar, de maneira mais evidente, o propósito do trabalho de mostrar os caminhos que os artistas, das artes plásticas, por exemplo, têm tomado em Mato Grosso do Sul para produzirem narrativas artísticas na atualidade. Se por um lado vários deles tomam das "impressões" (DERRIDA) como fardos artísticos do passado, outros, por sua vez, têm tentado trabalhar na contramão da simples manutenção de narrativas históricas como repertórios artísticos. Dos primeiros, a exemplo do artista da "Série" antes apontada, têm trabalhos que fazem ressaltar características estilísticas de movimentos artísticos e artistas históricos como se essas fossem as únicas formas de produzir pintura, por exemplo, na atualidade. Nesse sentido, temos na pintura da contemporaneidade sul-mato-grossense a grande maioria de artistas que resgatam as memórias renascentistas, impressionistas, fovistas, entre tantos outros estilos/movimentos, atestando estarem produzindo memórias e arquivos atuais para a arte local. (AUTOR; NOLASCO, 2015). Sobre esses "artistas" pintores que resgatam as histórias, memórias e arquivos alheios como forma de produção artística, temos no estado grupos concentrados em reproduzir as paisagens naturais do local. Pois, da mesma maneira que a imagem do boi, as paisagens exóticas do Pantanal, ícones indígenas, das aves e dos animais silvestres ilustram grande parcela das pinturas desses artistas locais. Igualmente 
ao patrocínio e crítica recebida pelos promotores do Estado e da crítica local quando se trata da imagem do boi, as paisagens naturais e os indígenas locais ganham destaque porque suscitam uma imagem de promoção turística, por exemplo, do local. Ou seja, igualmente ao bovinoculturismo artístico - que é ressaltado como característica da pintura local -, as paisagens exóticas e índios locais também corroboram uma ideia de arte que promove uma narrativa ancorada em histórias, arquivos e memórias alheias para ilustrar a cultura do local. Contrariando assim, a noção de paisagem "inventada" por Anne Cauquelin: "o que se pode ver, a paisagem pintada, é a concretização do vínculo entre os diferentes elementos e valores de uma cultura, ligação que oferece um agenciamento, um ordenamento e, por fim, uma “ordem”à percepção do mundo. (CAUQUELIN, 2007, p. 13-14)

Tomemos então do tema temporal na discussão: “Agouro, Ágora, Agora” e sujeitos, espaços e narrativas. Dois tipos de artistas aqui são importantes: os primeiros, artistas que discorrem de tempos múltiplos como agoras na arte contemporânea, tem obras plásticas que situam, por exemplo, tempos contraditórios relativos aos que vivemos (figuras 9, 10, 11 e 12). Nesse sentido, uma noção outra de plasticidade e visualidade corroboram para ler obras tanto plástico-visuais, tanto quanto de outras linguagens artísticas por tomar da hibridez entre elas na atualidade. (AUTOR, 2017).

\begin{abstract}
Diante desse quadro instável, parece ser necessário explicitar, mesmo que em seus traços mais básicos, o que está em jogo nas produções recentes de vários artistas que têm buscado enfrentar, cada um à sua maneira, essa situação de descompasso entre a realidade e sua tradução no campo do sensível. Em particular, discutir o sentido último de a arte representar o mundo de maneiras distintas das legitimadas; de figurar o lugar em que se deseja viver no futuro, na medida em que esse lugar projetado é diferente do mundo existente agora. Parece ser preciso, por fim, atentar para a potência que a arte embute de não somente resistir ao que aí está e antecipar o que pode vir, mas de algum modo participar da invenção desse lugar que ainda não há. (ANJOS, 2017, p. 1)
\end{abstract}

Já do segundo grupo de artistas importam aqui aqueles que insistem em situar suas obras no passado Modernista ou Clássico a fim de galgar, agourando-as, aqueles lugares canônicos para si. Por exemplo, obras e artistas que insistem em reproduzir os passados, memórias e histórias da Arte, como aquele da "série..." já citada, (figura 8) para se firmarem no presente visando um lugar estável no futuro. Nesse sentido, nem sempre as obras desses artistas estarão inscritas nas ideias de Arte Contemporânea, mas apenas rotuladas em arte de um tempo atual. Do mesmo jeito, vivendo em função do passado, esses artistas lidam com seus próprios tempo, espaço, memórias, histórias e sujeitos da atualidade.

De início, é preciso lembrar que qualquer produção artística está sempre ligada, com menor ou maior evidência ou consciência, aos lugares e aos tempos vividos por seus 
autores. Aquilo que é inventado pelos artistas, ou mediado por suas subjetividades, sempre deixa transparecer, como sintoma ou como análise, a situação e o contexto específicos que lhe serve de chão e calha. São criações que estabelecem e que reiteram, a cada ambiente e a cada momento, um conjunto de pistas e de vestígios que desenham maneiras singulares de estar no mundo, próprias a uma dada comunidade. É nesse sentido que se pode dizer que essas criações são equivalentes sensiveis de uma determinada realidade e se configuram, portanto, como práticas de representação. (ANJOS, 2017, p. 2)

Ainda estão inscritos nesse segundo tipo de artistas, os que produzem na contemporaneidade e os que tratam as imagens, na grande maioria, como iconografia da cultura local (enquadrada em discursos políticos como avalizadores financeiros e/ou discursos críticos que os sustentam como arte local), alguns artistas que pintam paisagens e imagens como pintavam os artistas históricos. Vinculados a uma espécie de associação artística local na grande maioria pintores de paisagens naturais do estado, de reprodução da iconografia indígena, de artistas que tratam a contemporaneidade com "naturalidade" consequente dos movimentos artísticos do passado, a partir da adoção da pura "técnica" de reprodução das técnicas artísticas históricas - artistas têm buscado lugar ao sol na produção local atual. Antes de continuar quero reforçar que tudo tem lugar na contemporaneidade quando pensamos de uma perspectiva não colonial e/ou subalterna, por exemplo, mas não é possível considerar que tudo também se inscreve como produção artística e de conhecimento e identitária locais simplesmente pelo fato de reproduzirem as imagens iconográficas (políticas e/ou econômicas) do lugar.

É nisso que a consciência estruturalista é a consciência pura e simples como pensamento do passado, isto é, o fato do geral. Reflexão sobre o realizado, o constituído, o construído. Historiadora, escática e crepuscular por situação. Mas na estrutura não há apenas a forma, a relação e a configuração. Há também a solidariedade; e a totalidade, que é sempre concreta. (DERRIDA, 2009, p. 4)

Portanto, esse grupo de artistas, que entendem o papel do Estado-nação como única forma de valorização e polarização das produções locais - porque esses retratam o lugar a partir dos discursos que o Estado vende, por isso acham que o "Governo e prefeitura não adquirem nossas obras" (GARCIA, 2017, p. 2) - estruturam a produção local na história e em memória alheias. Esses artistas, produzindo em praças e se reunindo em grupos variados deles, faz muitos anos, vêm colocando a produção artística local como uma produção que apenas retrata uma ideia única de identidade artística local: como sugeriu Homi K. Bhabha (1998), uma "nação" que é representada por uma "única narração".5 Nesse grupo de artista, vários

\footnotetext{
${ }^{5}$ Naquele texto aqui já referendado - "Três décadas de arte em Mato Grosso do Sul: balanços e desafios futuros" - trato longamente da forma bipolar que as produções artísticas e críticas locais tratam das relações de identidades locais - instável x estável - no estado de Mato Grosso do Sul.
} 
produzem "gatinhos", cachorrinhos, ipês, aves coloridas, pântanos, índios, matas, pinturas rupestres, declamam poesias românticas, como se tudo fosse "flores" na história do Estado, sustentam discursos paisagísticos e políticos - altamente comercializados pelo Estado-nação dentro e fora do local - estruturando a produção artística em um lugar da história alheia como se essa fosse nossa.

Por último, ao que se refere a esses grupos, tomo de artistas que, eles próprios, "levam" suas produções artísticas a lugares institucionais ou comerciais como se fossem as ágoras antigas (figuras 5, 6 e 7), a fim de popularizá-las em contextos múltiplos da arte. Indiferentemente do quão isso acaba por influenciar nas diretrizes dos seus "projetos" artísticos pessoais. Desses artistas, que talvez se inscrevam contemporâneos e/ou artistas da atualidade, obras e discursos sobre esses servem para situar a questão fundamental: mostrar a situação dos múltiplos agoras da produção artística e artistas do nosso tempo: “Agouro, Ágora, Agora". Dos dois grupos, na grande maioria, acabamos por ver que se sustentam, ou melhor, são sustentados pelos discursos políticos e econômicos nos tempos dos agoras atual. Ora são inscritas como produções que apenas (re)produzem histórias alheias, ora falam ou promovem falas a respeito de seus trabalhos, visando situação nas ágoras contemporâneas: museus, galerias institucionais, galerias comerciais ou em outros espaços avalizados pelo Estado-nação. Essas discussões evidenciam que nos três grupos de artistas e suas obras, esses dialogam de forma diferente com o conceito de identidade contemporâneo. Ou seja, do primeiro grupo, artistas da Arte Contemporânea, espera-se um tratamento das várias identitárias da contemporaneidade. Distintamente daquela noção de identidade estável, edificada na modernidade, que está mais presente nos artistas que agouram e transportam para ágoras suas obras, enquanto aqueles primeiros primam pelas várias noções identitárias, vistas como contraditórias, dos múltiplos agoras contemporâneos. O contemporâneo, portanto, prima pelas múltiplas identidades, lugares e sujeitos que circulam nas fronteiras, espaços, cidades e instituições da arte ou não.

No séc. XX, vem ocorrendo uma "revolução cultural" no sentido substantivo, empírico e material da palavra. Sem sombra de dúvida, o domínio constituído pelas atividades, instituições e práticas expandiu-se para além do conhecido. Ao mesmo tempo, a cultura tem assumido uma função de importância sem igual no que diz respeito à estrutura e à organização da sociedade moderna tardia, aos processos de desenvolvimento do meio ambiente global e à disposição de seus recursos econômicos e materiais. Os meios de produção, circulação e troca cultural, em particular, têm se expandido, através das tecnologias e da revolução da informação. (HALL, 1997, p. 2) 
Neste sentido, tomo das discussões sobre os "Agouro, Ágora, Agora" na arte atual (contemporâneas ou não), sobre os espaços, limites, fronteiras, sujeitos e identidades de autores culturalistas e pós-coloniais, por exemplo, que discutem os sujeitos-bios, espaçosgeos e as narrativas-grafias, BIOgeografias (AUTOR, 2016), nas produções artístico-visuais que obrigam-nos (des)focalizar os tradicionais conceitos, tempos, espaços, sujeitos, memórias e histórias da produção de lugares não situados na Europa ou nos Estados Unidos - lugares não considerados produtores de arte, cultura e conhecimentos. Pois, esses autores estão, por exemplo, cobrando dos artistas, nas obras de arte e/ou nas suas representações sobre as culturas, a apresentação mais real de sujeitos, espaços e narrativas associados às nossas realidades para além daquelas tratadas por artistas e críticos Modernos e Clássicos "Ocidentais" reverberados como memórias e histórias fundamentais para constituições de tudo nos "Agouro, Ágora, Agora" contemporâneos. Esta questão teórico-crítica obriga-nos, numa discussão desta natureza, (re)verificação dos fatos (im)postos pelas/nas produções visuais e a revisão dos conceitos de memória e história e, logo, dos conceitos de obra de arte (Clássico) bem como o de estética (Moderno) que sustentam as obras artísticas até então produzidas na grande maioria das vezes. Nesta empreitada as ideias de cronologia, continuidade e de passado histórico como únicos mecanismos para explicação do presente e previsão do futuro acabam por desmoronar-se por entender as múltiplas histórias locais em oposição à ideia de projetos globais. Dos clássicos e modernos, as histórias e memórias, não são descartados, mas não são tomados como únicos panos de fundo das produções que são emergentes de sujeitos, lugares e grafias - BIOgeografias - nas fronteiras sul do Centro-Oeste Brasileiro, por exemplo. Quando tomo desses outros lugares, ilustrados neste trabalho por Mato Grosso do Sul com sua tríplice fronteira e com seus limites territoriais com outros cinco Estados Brasileiros, são das histórias locais e, igualmente dos sujeitos, espaços e das narrativas emergentes que evidenciam “Agouro, Ágora, Agora” outros nas produções artísticas aqui abordadas de uma perspectiva epistêmica também outra; por conseguinte diferente da de continuidade e/ou cronologia. Essas histórias locais outras, foram, são e serão (passado, presente e futuro), se não (re)verificados o foco de "leituras e leitores" dessas obras e sujeitos (contemporâneos e/ou artífices da atualidade), sempre vistos como continuidades daquelas histórias clássicas e/ou modernas. Do mesmo jeito, lugares fora dos centros serão os que farão emergir esses discursos outros que nunca são produtores de arte, cultura e conhecimentos (através ou não da arte - agora sem rótulos temporais de passado, presente ou futuro). Portanto, seremos apenas ilustração e continuidades daqueles. 


\subsection{Produção e/ou reprodução de arte, cultura e conhecimento}

Nessas últimas quase quatro décadas, a completarem-se no próximo dia 26 de agosto (a cidade tem fundação em 21 de junho de 1872 (145 anos), mas sua emancipação data de 26 de agosto de 1899 (117 anos)), as produções artísticas locais, bem como a cultura de MS estiveram vinculadas a duas noções de arte e cultura bovinas expostas antes. Sobre isso, em 1967 Mário Pedrosa já falava da pintura "primitiva" de Humberto Espíndola que, como apresentada antes e que ainda retomo aqui mais tarde, vai inaugurar e manter a imagem do boi na arte sul-mato-grossense (ainda que à época falássemos de Mato Grosso), compósita de imagens do boi:

As telas que vi dele são todas inspiradas por um tema: o boi. O boi não como o pachorrento ruminante dos currais ou de outras cenas bucólicas, mas o boi na sociedade, isto é, o boi-dinheiro, o boi, símbolo de riqueza de Mato Grosso. Um de seus quadros se intitula: Glória ao boi nas alturas; um outro: Boi \& society; e o terceiro: Boi alado nas asas do dinheiro. Simpatizei com esses títulos, pois indicam que o autor deles tem seqüência nas idéias. Não seria, então, um improvisador, um seguidor de modas. Felizmente, também, não é aposentado como mais um desses "primitivos" que chegam dos cafundós do Brasil para regalo do burguês enfastiado da metrópole. (PEDROSA, 1967, s/p)

Já, a perspectiva que se quer aqui entendida, no segundo caso, o bovinoculturismo como estilismo artístico - atendendo às demandas da Arte Moderna que rompe com o clássico, mas passa a estabelecer movimentos artísticos localizados em substituições a outros e, por conseguinte, representação dos lugares parecendo dar oportunidades iguais a todos os lugares e sujeitos - visa dar continuidade e inscrição de algumas reproduções artísticas às ideias de arte, cultura e conhecimentos alheios migrados para o local desde que este é compreendido enquanto tal (ou seja, pós-divisão de MT em 1977 até a contemporaneidade). ${ }^{6}$ Vários artistas, "sugerindo" evidenciar aquele "primitivo", agora claro, tardio, ressaltado por Pedrosa, continuam ilustrando obras com a imagem e iconografia bovinas como se fossem representações identitárias na contemporaneidade. E, neste segundo caso ainda, há, de maneira muito clara e evidente, a contribuição dos poderes políticos e/ou econômicos para a sustentação dessa ideia de "cultura do boi" como estilo a fim de manutenção das fazendas que criam o gado e plantam os grãos via validação deste lócus - Mato Grosso do Sul - como a

\footnotetext{
${ }^{6}$ A Arte Moderna tem, historicamente, um rótulo de Período Artístico que fez evidenciar produções de diferentes lugares como se todo e qualquer sujeito e lugares pudessem produzir igualmente à Europa ou aos Estados Unidos. Se por um lado isso pareceu dar sentido às produções de lugares fora desses centros, por outro as leituras críticas Modernas e Contemporâneas da Arte Moderna não permitem até hoje inscrever arte, culturas e conhecimentos de outros lugares que não estejam vinculados às ideias de continuísmos e cronologias da produção Moderna. É neste sentido que vamos ter, por exemplo, períodos Modernistas espalhados por toda a América Latina.
} 
"maior" terra da soja e do boi. Nesse sentido, ilustra, ainda, uma passagem de Edgar Nolasco que evidencia a dificuldade de conceituar "puro e simplesmente" esse lugar de "fronteiras" atravessadas, contrabandeadas e transculturadas meramente como lugar que (de)marca. Pois as fronteiras são "Lugares" que demandam uma desconstrução de tudo que já fora posto pela História da Arte que alguns ainda insistem em dizer ter uma "[...] nossa arte [do] Brasil Central, pantaneira e genuína [...]" (GARCIA, 2017, p. 2) ou alguns outros que a percebem como uma arte de "cor local" estabilizada e exclusivista - uma ideia de artistas genuínos da terra impera nos discursos que defendem essa arte do exótico como identidade do lugar. A ideia é, portanto, que, vários desses artistas que usurpam a imagem do boi e uma suposta ideia de iconografia exclusivamente local, acabam por evidenciar com seus trabalhos quase primários, ou primitivos como ressaltou Pedrosa, uma identidade estável que - ilustrados pela figura 4 - faz muito tempo não corrobora mais pensar o sujeito na sua individualidade; pensemos então no caso de um Estado da federação como Mato Grosso do Sul que é múltiplo em todos os sentidos.

As coisas encontram-se aqui numa condição de contrabando cultural sem origem, sem começo, nem fim. Nessa importação clandestina de mercadorias culturais estrangeiras e sem fiador, contrabando é sinônimo de transferência, transculturação, transformação, lugar por excelência de um sujeito-transeunte em trânsito. Eterno entre-meio, entre-espaço, entre-tempo, constituindo uma existência espacial cujo espaço é antes existencial: por ele as gentes passam, as manifestações culturais são geradas, e ambas atravessadas por uma apologia do afeto que marca a diferença cultural do bio do sujeito e da cultura localistas, como a uma pele de boi marcada a ferro-e-fogo. Não por acaso entendemos que o que é da ordem da especificidade de uma cultura passa por uma afetividade (Canclini) da nação localista, e cujo sentimento é também, por sua vez, de ordem cultural. (NOLASCO, 2012, p. 30)
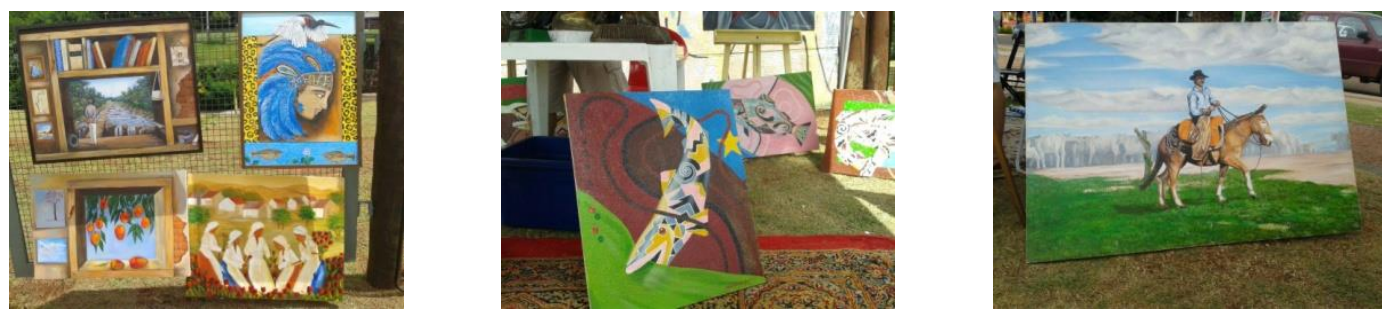

Figura 4 - Imagens de trabalhos expostos em feiras populares na cidade de Campo Grande, MS promovida por uma

Confraria de Artistas denominada de Confraria Sociartista.

Fonte: CONFRARIA SOCIARTISTA. HOME PAGE - FACEBOOCK.

Convidamos músicos, atores, poetas amigos, para participarem do evento. Temos uma Feira de Artes todos os primeiros domingos do mês, das 9 às 16 horas. E nos segundo sábado, das 16 às 22 horas, nos mesmos moldes das ocupações, com artistas pintando ao vivo e expondo suas obras e músicos, poetas, atores e outras manifestações artísticas se apresentando. (GARCIA, 2017, p. 2)

Ilustra, portanto, as passagens de Nolasco e Garcia, bem como a figuras antes expostas, a emergência de tomar das fronteiras locais em Mato Grosso do Sul longe da ideia exclusivista de marcos demarcatório. Pois esses estão, antes de qualquer coisa, situados em discursos 
políticos e econômicos que homogeneízam as identidades, os lugares, por conseguinte as produções artístico-culturais e os discursos que emergem dos lados das fronteiras.

Esses fatos, portanto, resolvem a nossa questão antes levantada: NÃO é possível tornar individual o local a fim de atender os sistemas discursivos dos poderes instituídos (político e econômico) e, menos ainda, deveria ter o apoio para isso de alguns artistas ou artífices apoiando tal postura. As particularidades, "marcas, ou as "rasuras", como tratou Jacques Derrida ao falar de diferenças, necessariamente devem ser respeitadas para que essas mantenham as alterações e façam alterações em quem circula nas fronteiras que afastam, mas ao mesmo tempo aproximam (HISSA, 2002) as biogeografias. Por último, essas são questões que acabam por demonstrar que as práticas artístico-culturais produzem e não reproduzem arte, cultura e conhecimento de outros locais hegemônicos, no local dessa tríplice fronteira (Brasil/Paraguai/Bolívia), talvez sem fazer "inventAÇÕES" como pensam uns, mas de fato contando as verdadeiras histórias e memórias locais.

\section{Conclusões}

Expor essas mazelas da produção pictórica local (na plástica, na grande maioria), não quero parecer estar contribuindo para o fracasso dessas práticas artísticas locais e reforço do que vem de fora: isto é papel da crítica que está posta no estado nesses últimos quarenta anos. Contrariando esse desejo comum de artistas e críticos localistas, a intenção desta pesquisa como um todo é de fazer ressaltar uma problemática que precisa emergencialmente ainda ser tratada sobre as produções artísticas locais. Se por um lado a falta de organização de alguns grupos de artistas faz evidenciar as fragilidades desses, por outro a organização deve estar embasada em reformulações que se voltam para o local cultural - não para seus próprios umbigos. Ou seja, não adianta nenhuma estruturação societária que esteja ancorada em proposições (artísticas, teóricas, críticas e pedagógicas) que não tenham relação com o local. Olhar para as produções do passado com romantismo e pieguice não faz a contemporaneidade perfurar espaços como salientou Canton. Por exemplo, Ana Ruas é uma dos artistas institucionalizadas em MS. Para o bem ou para o mal, a situação promove à artista circulação nos espaços institucionais do Estado. Pintora de telas, painéis e murais na capital Campo Grande, Ruas tem carreira artística considerável, mas está também amparada em discursos hegemônicos que a mantém no cenário da arte local. Com apoio institucional (Estadual e Municipal), a artista promove cursos, oficinas, eventos institucionais e expõe em espaços do poder público. Ana Ruas é a típica artista contemporânea que em Mato Grosso do Sul parece 
pactuar de uma ideia identitária de arte comum a todos sobremaneira defendida e difunda pelo Estado.

Se por um lado os trabalhos de Ruas, quase em geral, dos antigos aos atuais, situam-se sensivelmente para a maioria das pessoas do lócus sul-mato-grossense, de outro lado, tomando de Moacir dos Anjos (2017, p. 2), "Esse comum representado pela arte não abrange, entretanto, tudo e todos que supostamente pertenceriam, a cada momento, a determinado agrupamento identitário ou mesmo geográfico." Portanto, sem a ideia de que aquelas obras da artista se valem de características exóticas da cultura que estariam inerentes a qualquer sujeito local, bem como ao forte apelo infantil do seu projeto, a sua última obra, tendo em vista que MS tem relação diaspórica (HALL, 2003) com outros lugares, "não abrange todas as equivalências sensíveis que seriam possíveis de ser feitas como representações de uma realidade inscrita em tempo e lugar determinados." (ANJOS, 2017, p. 2) Isso, tendo em vista que nem todos se situam nas "belas" paisagens retratadas pela artista na sua última exposição ilustrada por reproduções das obras (figuras 5, 6 e 7); essa "floresta encantada" da artista encanta identidades formuladas pelo poder público mais uma vez.
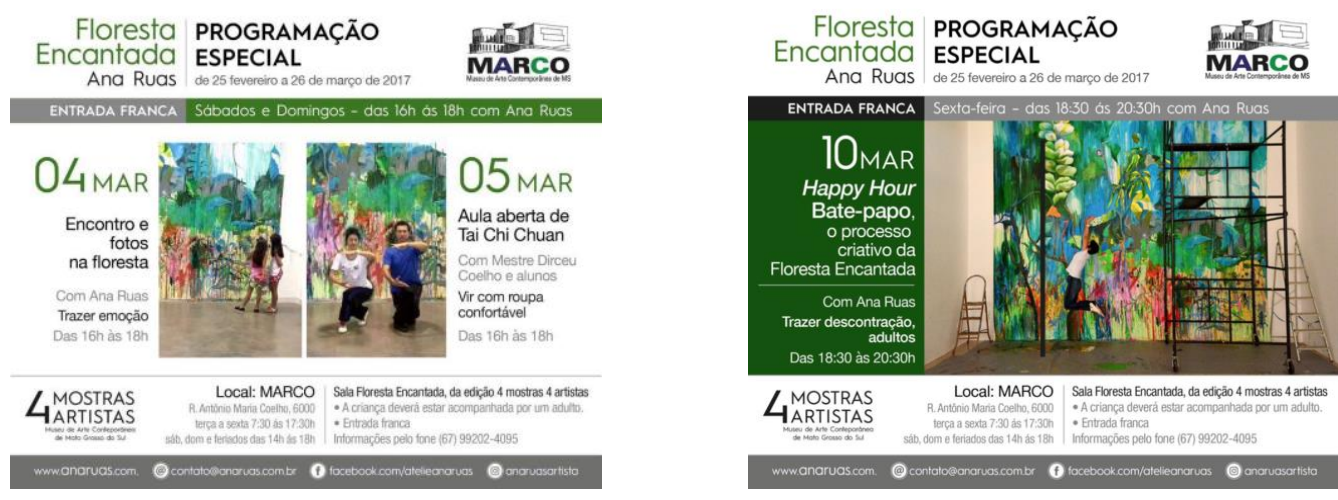

Figura 5 e 6 - Imagens de divulgação dos Projetos institucionalizados da artista. $^{7}$

Fonte: Fotos de divulgação de internet.

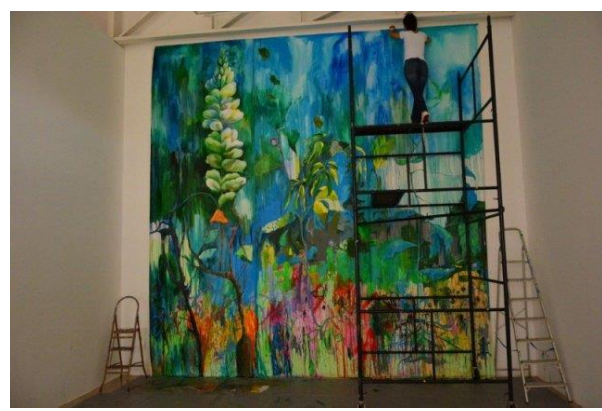

Figura 7 - Imagens de divulgação dos Projetos institucionalizados da $\operatorname{artista.~}^{8}$

\footnotetext{
${ }^{7}$ Imagens de divulgação disponíveis em: http://www.spms.com.br/content/mostra-ana-ruas-floresta-encantada acessadas em 02 de julho de 2017.
} 
Fonte: Fotos de divulgação de internet.

Outro artista que sempre consta da cena artístico-plástica sul-mato-grossense é Humberto Espíndola. Suas obras da Série "Divisão do Estado" (1977-1978) são fundadoras da "bovinocultura" em Mato Grosso do Sul com - a figura 8 é mais uma ilustração das que compõe a série. Essas obras construíram nas narrativas artísticas locais, nos diferentes agoras - passado, presente e insistem para o futuro -, igualmente instalaram-se nas múltiplas ágoras institucionais do Estado e, também, são contribuições para o agouro do passado áureo artístico clássico e moderno defendido pelos discursos do Estado. Se de alguma forma as obras do artista retratam a cultura bovina local como cultura de boi, por outro elas contribuem insistentemente e são reforçadas pelas leituras críticas locais como obras que nos representam como cultura única e exclusivamente do boi. ${ }^{9} \mathrm{Na}$ obra "Dividire per multiplicare", 1978, fica ilustrada a corpora do animal em cores nacionalistas com insígnia das iniciais MS que situacionalizam o discurso daquele artista tratar-se de MS. Do mesmo jeito a cara bovina é iconografada na obra, a partir da imagem de contorno do mapa geográfico do Estado, que tem, ironicamente, formatos iguais.

Da mesma forma que aquilo que é representado em parlamentos não abrange tudo que concerne a cada um dos que vivem sob suas circunscrições. De fato, nenhuma representação da realidade se confunde com essa mesma realidade, estando sempre aquém do universo representado. (ANJOS, 2017, p. 2)

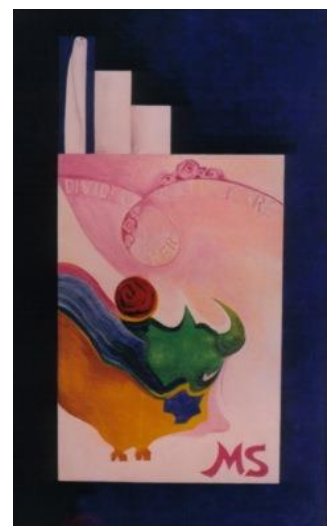

Figura 8 - Dividire per multiplicare, 1978. Óleo sobre tela - 136 x $81 \mathrm{~cm}$.

Fonte: site do às obras do artista plástico Humberto Espíndola.

De Ana Ruas e Humberto Espíndola, tratados a partir das suas pinturas, posso dizer que se situam na ideia de identidade cultural que toma de imagens que representam o todo a partir de

\footnotetext{
${ }^{8}$ Imagens de divulgação disponíveis em: http://www.spms.com.br/content/mostra-ana-ruas-floresta-encantada acessadas em 02 de julho de 2017.

${ }^{9}$ Esta questão de cultura de boi ou cultura do boi sobre a produção artística de Mato Grosso do Sul está mais bem tratada em (AUTOR; NORONHA, 2015)
} 
Única ideia de paisagem local da cultura de MS - o agora sustentado pela ideia de imagens clássicas e modernas. Se Ruas faz de redes e da flora locais suas pinturas, Espíndola continua reforçando o boi como representação fiel da sociedade da fronteira sul do Centro-Oeste brasileiro. Ambos fazem da cultura de MS repositório das suas paisagens e bois e (re)produzem obras na atualidade.

Mais um artista contemporâneo sul-mato-grossense que tem tomado evidência também fora do Estado é Evandro Prado que hoje está morando em São Paulo e acaba de abrir sua primeira individual, intitulada "Sem berço", na mesma temática barroca dos seus últimos trabalhos (figuras 9, 10, 11 e 12). Desde sua série "inaugural" - Habemus cocam (figura 13), (maio/junho de 2006) - no cenário artístico contemporâneo sul-mato-grossense, suas obras em pinturas, objetos e instalações têm um forte apelo religioso que nos remete ao período clássico entre o Renascimento e o Barroco. Nas obras dessa última exposição os trabalhos estão com tal tema bem mais evidente. Mas, em contrapartida, as obras de Evandro Prado vêm tratando também de uma perspectiva até irônica a situação ex-colonial do Brasil. Se de um modo as obras retomam constantemente alguns aspectos clássicos da arte europeia, que faz com que a obra do artista seja reconhecida em lugares institucionais e fora deles em MS, por outro o artista tem tratado de uma questão bastante pertinente para a produção artística e as identidades socioculturais, especialmente, de sujeitos e de lugares de fora dos centros, que sequer alguns artistas, críticos e público já reconheçam.
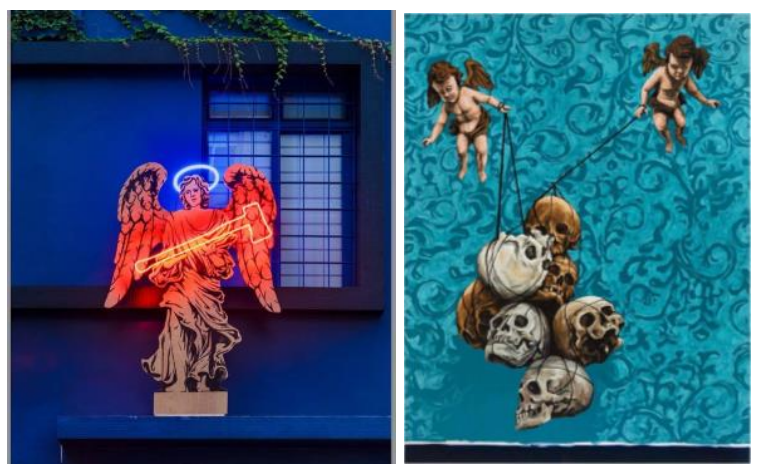

Figura 9 e 10 - respectivamente, "Anjo da Anunciação" - instalação montada na entrada da Galeria Jairo Goldenberg - e "Barroco", OST, uma das pinturas da exposição. Higienópolis, SP. ${ }^{10}$

Fonte: site do às obras do artista plástico Evandro Prado.

Mais uma vez são pertinentes as palavras de Moacir dos Anjos ao tratar das representações na arte brasileira ao dizer que

\footnotetext{
10 Todas as imagens das obras de Evandro Prado foram retiradas no site do artista. Disponível em: http://www.evandroprado.com.br/p/pinturas.html - acessado em: 01 de julho de 2017.
} 

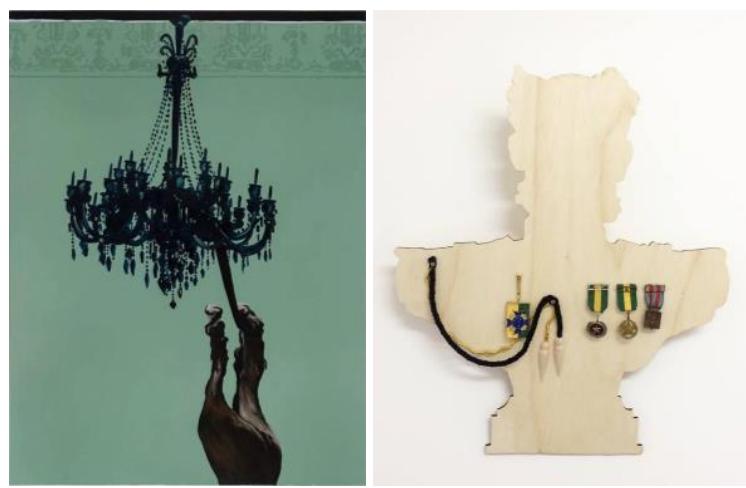

Figura 11 e 12 - respectivamente, "Proclamação da República”, pintura OST, exposta na Galeria Jairo Goldenberg - e

"Marechal Deodoro", um dos objetos da exposição. Higienópolis, SP.

Fonte: site do às obras do artista plástico Evandro Prado.

Toda representação é sempre e inescapavelmente um recorte de um universo mais amplo atravessado por uma irredutível diversidade; uma abstração de um todo inapreensível por ser, em certa e relevante medida, opaco ao olhar de qualquer um dentre os muitos que ali coexistem. (ANJOS, 2017, p. 2)

Se paisagem e fauna são opacos para alguns, no caso da colonialidade não o pode ser.

Sobre a exposição "Sem berço” a divulgação na Revista Dasartes (2017) diz:

Os trabalhos dessa exposição suscitam reflexões sobre a formação da sociedade brasileira. A discussão conceitual busca expor as contradições de um país continental, rico e belo, mas colonizado, explorado, devastado pela cobiça. Um país de extremos, desigual, formado por paradoxos. Abençoado pela Igreja Católica e dirigido por uma oligarquia pretensiosa que fez riqueza a partir do sangue dos nativos e do trabalho de homens negros escravizados. O artista é provocativo e suas pinturas são inquietas. Proporciona êxtase e mal-estar ao colocar em cheque a história "oficial" e seu culto aos "heróis" da nação.

Tanto em "Habemus cocam" como em "Sem berço" e em outros trabalhos do artista sul-matogrossense é possível evidenciarmos a relação clara das obras e o discurso que evidencia leituras que remontam às relações de poder estabelecidas desde sempre na produção artística brasileira em relação aos centros artísticos. Ainda é possível dizer que Evandro Prado tem evidenciado perspectivas outras da arte não só sul-mato-grossense, mas brasileira que carregam em si as questões de heranças (sem berços) e religiosidades (também habemus Cristo) e não apenas paisagens e animais como representações imagéticas ancoradas em exotismos e animalidades.

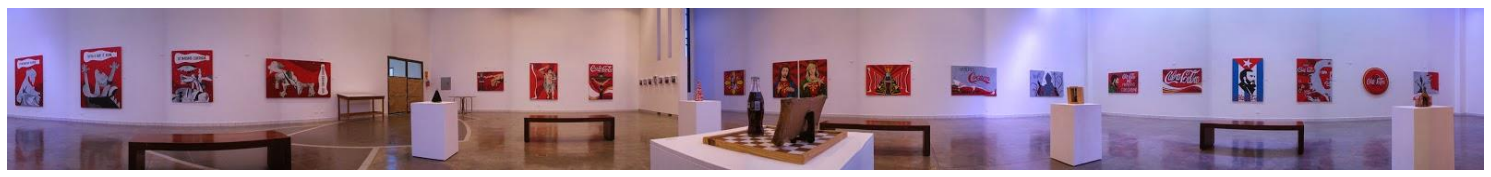

Figura 13 - Panorâmica da exposição Habemus cocam, realizada no MARCO (maio/junho de 2006).

Fonte: site do às obras do artista plástico Evandro Prado.

Enfim, apesar das distinções nos fatos aqui tratados - das obras, sujeitos, espaços, narrativas, identidades, memórias e histórias (próprias e alheias) -, preferi não me ater 
separadamente em cada coisa para não cair no lugar muito analítico ao qual não faço questão de ocupar. Pois, é bastante natural para a crítica tradicional confrontar questões e fatos, a fim de vislumbrar relações entre "Agouro, Ágora, Agora”, do passado, presente e futuro, ao analisar pura e simplesmente as obras e apresentar uma visada qualitativa dessas. Tomo disso, à medida que, como sugeriu Jacques Derrida (2008), grosso modo, a desordem dos discursos na atualidade (crítico, artístico e pedagógico), na arte ou em qualquer outra disciplina, vai estar em evidenciar diferenças (différences) culturais em detrimento de qualidades técnicas, temporais e estilísticas.

Portanto, tomando essas premissas aqui apresentadas, este trabalho discutiu acerca da "cultura do boi" e da "cultura de boi" em Mato Grosso do Sul na tríplice fronteira como repositório cultural e como reprodutório de cultura como controle da cultura local sul-matogrossense nesse espaço histórico e geopolítico (Brasil/Paraguai/Bolívia), a partir da noção de biogeografia e paisagens biográficas como epistemes para uma arte descolonial. Ou seja, que todo o lugar-geográfico faz emergir arte, cultura e conhecimento a partir do sujeito-bio e geoespaços com suas narrativas-grafias - BIOgeográficas - e que essas não são melhores nem piores que outras práticas, sujeitos e lugares, mas são diferentes graças as suas especificidades. São paisagens outras, poderíamos assim dizer. Nesse sentido, o trabalho tomou de afazeres e fazeres artísticos e teóricos para efetivar a proposta de discutir essas produções artísticas e as biogeografias dessa fronteira sul, nas diferentes linguagens da arte com suas identidades múltiplas que habitam as fronteiras, que estão produzindo arte e conhecimento e circulando entre os espaços, tomando como ilustração a "imagem" simbólica ou real - do boi, para produção ou emersão desse/nesse espaço. Bem como foi também a ideia aqui ex-posta de debater sobre os trabalhos, sujeitos e artistas que estão cooperando na reprodução da arte, da cultura e do conhecimento vindos, especialmente do além-mar, sem nenhuma preocupação epistêmica de (trans)tradução com o local cultural sulmato-grossense. Afinal, a saber, essa é a terra da "cultura boi", mas do boi como bovinocultura ou bovinoculturismo?

\section{Referências}

ANJOS, Moacir dos. A arte brasileira e a crise de representação. Revista ZUM/IMS Revista de Fotografia. São Paulo: Instituto Moreira. Publicado em: 07 de julho de 2017, p. 1-6. Disponível em: http://revistazum.com.br/colunistas/crise-de-representacao/. Acesso em: 10 jul. 2017. 
BHABHA, Homi K.. DissemiNação: o tempo, a narrativa e as margens da nação moderna. In: _. O local da cultural. Tradução Myriam Ávila, Eliana Lourenço de Lima Reis, Gláucia Renate Gonçalves. Belo Horizonte: Ed. UFMG, 1998. p. 198-238.

Autor; NOLASCO, Edgar Cézar. "Entre saudades e contaminações: o artista à procura de um olhar perdido em Mato Grosso do Sul”. RAÍDO - Programa de Pós-Graduação em Letras da Universidade Federal da Grande Dourados (UFGD), v. 4, n. 7, p. 181-205, jan./jun. 2010. ISSN 1984-4018. Disponível em: http://ojs.ufgd.edu.br/index.php/Raido/article/view/576/531. Acesso em: 22 jul. 2017.

Autor. BIOGEOGRAFIAS OCIDENTAIS/ORIENTAIS: (i)migrações do bios e das epistemologias artísticas no front. Cadernos de Estudos Culturais: Ocidente/Oriente: migrações, Campo Grande, MS: Ed. UFMS, v. 8. n. 15. p. 97-144, , jan.-jun., 2016.

Autor; NOLASCO, Edgar Cézar. Do moderno ao contemporâneo, o boi insiste em manter-se personagem da obra de arte sul-mato-grossense. Porto arte: revista de Artes Visuais. Porto Alegre: Universidade Federal do Rio Grande do Sul. Instituto de Artes. Programa de Pósgraduação em artes Visuais. 20, n. 34, maio 2015, p. 69-88. Disponível em: http://seer.ufrgs.br/index.php/PortoArte/article/view/62311. Acesso em: 18 de jul. 2017.

HOMEMCOMOIMAGEM: uma leitura visual imagético/real dos trabalhos de conclusão da disciplina TIN/2016 dos alunos do 3o ano do curso de artes cênicas - UEMS. Revista da FUNDARTE / Fundação Municipal de Artes de Montenegro - FUNDARTE. ano 17, n. 33 (Jan./Jul. 2001). Montenegro, RS: Ed. da FUNDARTE, 2017, p. 70-92. Disponível em: http://seer.fundarte.rs.gov.br/index.php/RevistadaFundarte/article/view/445. Acesso em: 18 de jul. 2017.

Autor. Três décadas de arte em Mato Grosso do Sul: balanços e desafios futuros. In: Autor; TORCHI-CHACAROSQUI, Gicelma da Fonseca (Orgs.). Misturas e diversidades: reflexões diversas sobre arte e cultura contemporâneas. São Carlos, SP: Pedro \& João Editores, 2012. p. 73-92.

CANTON, Katia. Tempo e memória. São Paulo: Editora WMF Martins Fontes, 2009. [Coleção temas da arte contemporânea].

Narrativas enviesadas. São Paulo: Editora WMF Martins Fontes, 2009. [Coleção temas da arte contemporânea].

CAUQUELIN, Anne. A invenção da paisagem. Tradução Marcos Marcionilo. São Paulo: Martins, 2007. (Coleção Todas as Artes).

Home Page - Facebook - Confraria Socioartista. Disponível em: https://www.facebook.com/pg/confrariasociartista/photos/?ref=page_internal. Acesso em: 23 maio de 2017.

DERRIDA, Jacques. Gramatologia. Trad. Miriam Chnaiderman e Renato Janine Ribeiro. São Paulo: Perspectiva, 2008. (Estudos; 16). 
A escritura e a diferença. [tradução Maria Beatriz Marques Nizza da Silva, Pedro Leite Lopes e Pérola de Carvalho]. 4. ed.. São Paulo: Perspectiva, 2009. (Estudos; 271 / dirigida por J. Guinsburg).

Mal de arquivo: uma impressão freudiana. Trad. Claudia de Moraes Rego. Rio de Janeiro: Relume Dumará, 2001.

FIGUEIREDO, Aline. Arte aqui é mato. Cuiabá: Editora da UFMT, 1990.

GARCIA, Pedro Guilherme. "Pedro Guilherme Garcia: "Governo e prefeitura não adquirem nossas obras"". Entrevista postada em 16 de maio de 2017. In: FRAGA, Alex. Blog do Alex Fraga. Disponível em: http://blogdoalexfraga.com.br/2017/05/16/entrevistapedroguilherme/. Acesso em: 17 de maio de 2017, p. 1-7.

HALL, Stuart. A centralidade da cultura: notas sobre as revoluções culturais do nosso tempo. Educação \& Realidade, Porto Alegre, v. 22, n², p. 15-46, jul./dez. 1997. Disponível em: http://www.seer.ufrgs.br/educacaoerealidade/article/view/71361. Acesso em: 18 de jul. 2017.

HALL, Stuart. Da diáspora: identidades e mediações culturais. Organização Liv Sovik; Tradução Adelaina La Guardia Resende ... [et al]. Belo Horizonte: Editora UFMG; Brasília: Representação da UNESCO no Brasil, 2003. (Humanitas).

HISSA, Cássio Eduardo Viana. A mobilidade das fronteiras: inserções da geografia na crise da modernidade. Belo Horizonte: Editora UFMG, 2002. (Humanitas).

PEDROSA, Mario. In: Humberto Espíndola - 20 anos de Bovinocultura. Fundação de Cultura de Mato Grosso do Sul, Campo Grande, 1987. Disponível em: http://www.humbertoespindola.com.br/001-index_frameset.htm. Acesso em: 18 maio de 2017.

MIGNOLO, Walter D.. Histórias locais / projetos globais: colonialidade, saberes subalternos e pensamente liminar. Tradução Solange Ribeiro de Oliveira. Belo Horizonte: Editora UFMG, 2003.

MIGNOLO, Walter D.. Habitar los dos lados de la frontera/teorizar en el cuerpo de esa experiencia. Revista IXCHEL. Volúmen I, San José, Costa Rica, 2009, p. 1-22. Disponível em:

http://www.revistaixchel.org/attachments/047_Habitar\%201os\%20dos\%20lados\%20art_\%2 0Walter\%20Mignolo.doc\%29.pdf - acessado em: 30 de maio de 2013. Acesso em: 18 de jul. 2017.

NOLASCO, Edgar Cézar. Contrabando cultural. In: Autor; TORCHI-CHACAROSQUI, Gicelma da Fonseca (Orgs.). Misturas e diversidades: reflexões diversas sobre arte e cultura contemporâneas. São Carlos, SP: Pedro \& João Editores, 2012. p. 29-39.

REVISTA DASARTES. AGENDA - Evandro Prado | JB Goldenberg Escritório de Arte. Disponível em: http://dasartes.com.br/agenda/evandro-prado-jb-goldenberg-escritorio-dearte/. Acesso em: 15 julho de 2017. 